ISSN: 0213-2052 - eISSN: 2530-4100

DOI: https://doi.org/10.14201/shha202038113137

\title{
LA SOCIEDAD Y LA ECONOMÍA EN LA CIUDAD ROMANA DE CAPERA ${ }^{1}$
}

\section{Society and Economy in the Roman city of Capera}

\author{
Francisco CIDONCHA REDONDO \\ Universidad de Sevilla \\ fcidoncha@us.es
}

Fecha de recepción: 12-5-2019; aceptación definitiva: 2-03-2020

ORCID: https://orcid.org/0000-0002-0727-3648

RESUMEN: La sociedad y la economía de Capera tuvieron una serie de rasgos relacionados estrechamente con su situación geográfica. Por un lado, la fuerte influencia indígena está claramente manifestada en la onomástica de los individuos que vivieron en este núcleo urbano y en su territorium. Por otro lado, su propia ubicación en la conocida actualmente como "Vía de la Plata» constituyó un factor decisivo para su desarrollo. Este estudio pretende analizar las características y las peculiaridades de este municipium.

Palabras claves: Hispania; Lusitania; Onomástica; Vía de la Plata.

1. Este estudio se enmarca dentro del Proyecto del Programa Estatal de Generación de Conocimiento y Fortalecimiento Científico y Tecnológico del Sistema de I+D+i: «Marginación y visibilidad de la mujer en el Imperio romano: estudio de contrastes en los ámbitos políticos, jurídicos y religiosos» (PGC 2018-094169-B-I00). Al mismo tiempo, el trabajo ha sido realizado en el marco del grupo de investigación: "Campo y ciudad. Estructuras sociales, económicas e ideológicas en Andalucía y el Mundo Mediterráneo durante la Antigüedad» (HUM-441). Asimismo, quiero dar las gracias por la revisión de este artículo y la ayuda prestada por el profesor Dr. D. José Carlos Saquete Chamizo; no obstante, asumo cualquier error que permanezca en el mismo. 
ABSTRACT: Society and economy of Capera had some features closely related to its geographical situation. On the one hand, the strong indigenous influence is clearly manifested in the onomastic of the individuals who lived in that city and in its territorium. On the other hand, its location in the so-called "Vía de la Plata" was a decisive factor for its development. This study aims to analyze the characteristics and peculiarities of the society and the economy in this municipium.

Keywords: Hispania; Lusitania; Onosmastics; Vía de la Plata.

\section{EL MUNICIPIUM FLAVIUM CAPERENSIS}

Capera fue un municipium romano que se encontraba en el antiguo territorio de los Vettones $^{2}$. Se piensa que hubo un poblamiento prerromano anterior, pero su ubicación exacta no está constatada mediante excavaciones arqueológicas ${ }^{3}$. E. Cerrillo planteó la posibilidad de una dualidad de asentamientos al comienzo de la época romana, basando su teoría

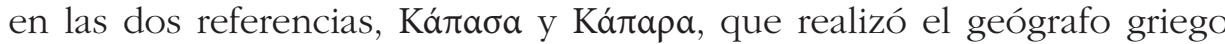
Ptolomeo en su obra ${ }^{4}$. Por su parte, M. Almagro propuso que Cáparra se habría convertido en un oppidum en los últimos momentos de la Edad del Hierro ${ }^{5}$.

El asentamiento permanente y definitivo estaría ya configurado en época augustea según sus restos arqueológicos ${ }^{6}$. Sería en ese mismo período cuando se emprendió la construcción de los edificios más antiguos del foro ${ }^{7}$. Capera tendría en ese momento la categoría de civitas stipendiaria dentro de la provincia de Lusitania ${ }^{8}$. Posteriormente, se convertiría ya en municipium en época flavia? ${ }^{9}$. Esta transformación jurídica

2. RoldÁn Hervás 1968, 75-76. Es numerosa la información sobre los vetones en las fuentes antiguas: Str. III, 1, 6; III, 3, 1-3 y III, 4, 12; Plin., N.H. III, 19; IV, 112 y IV, 116; Ptol. Geog. II, 5-7.

3. Algunos investigadores se han planteado si este asentamiento prerromano se encontraba en el mismo emplazamiento o en otro lugar cercano. Véase, por ejemplo, MéLida y Alinari 1924, 96; Cerrillo Martín de Cáceres 1994, 150; Calderón Fraile, Cano Ortiz, Cerrillo Cuenca, Heras Mora, Mejías del Cosso, Sánchez Barba y Silva Cordero 2000, 67.

4. Ptol. Geog. II, 5, 6 y 7. Cerrillo Martín de Cáceres 1994, 149 y ss.

5. Almagro Gorbea 1994, 13-75.

6. Alonso Sánchez, Cerrillo Martín de Cáceres y Fernández Corrales 1992-1993, 83.

7. Calderón Fraile, Cano Ortiz, Cerrillo Cuenca, Heras Mora, Mejías del Cosso, Sánchez Barba y Silva Cordero 2000, 67.

8. Plin. H.N. IV, 118.

9. Véase Canto y de Gregorio 1996, 240; Andreu Pintado 2006, 387-388. 
otorgó una serie de beneficios a la élite local, formándose el ordo decurionum y creándose las magistraturas romanas que se encargaban del gobierno de la ciudad. A partir del siglo iv, Capera fue perdiendo sus funciones cívicas, dando lugar al fin de su vida municipal ${ }^{10}$.

\section{Estudios REALIZADOS SOBRE CÁPARRA}

Las referencias sobre las ruinas de la antigua ciudad de Capera, hoy conocida como Cáparra, fueron frecuentes a partir del siglo xv. El gusto por el mundo clásico durante el Renacimiento hizo que algunos viajeros y eruditos, como Florián Docampo, mostraran interés por los vestigios de su pasado romano ${ }^{11}$. El arco tetrapylon llamó la atención de muchos de estos escritores, siendo numerosos tanto los grabados como las descripciones que se documentan de este monumento. Igualmente, hay que destacar la curiosidad de los estudiosos por los epígrafes que procedían de este lugar. Podemos mencionar entre ellos a Ciriaco de Ancona ${ }^{12}$. Los testimonios de los humanistas Mariangelo Accursio y Gaspar de Castro nos informan de la habitual reutilización de sus restos en las construcciones posteriores que se realizaron en las localidades cercanas ${ }^{13}$. Precisamente, un buen número de los ejemplos epigráficos que vamos a analizar se encuentran descontextualizados y diseminados entre los pueblos próximos por este motivo. La célebre obra España Sagrada, redactada en el siglo xvIII, también nos aporta datos sobre el estado de las ruinas ${ }^{14}$. A partir de esa época, los diferentes testimonios escritos describen el lugar ya como un despoblado. E. Cerrillo defiende que, quizás, el cese de la función hostelera que Cáparra había tenido hasta ese momento se deba a la creación de una nueva ruta de comunicación alternativa a la antigua calzada romana ${ }^{15}$. En el siglo XIx, P. Madoz recogió una entrada sobre Cáparra en su famoso Diccionario geográfico-estadístico-histórico de España y sus posesiones de Ultramar $^{16}$. En este trabajo aparece como un despoblado que conservaba numerosos vestigios de tiempos anteriores. En la misma centuria se inició

10. Cerrillo Martín de Cáceres 1998, 88; 2000, 163.

11. DOCAMPO 1544.

12. Gimeno Pascual 1997, 140.

13. Blázquez Martínez 1965, 6-7.

14. FlóREZ 1758, 54. También podemos encontrar descripciones sobre el arco de Cáparra en obras de finales del siglo xviII. Véase, por ejemplo, Ponz y Piquer 1784 y De Masdeu 1800.

15. Cerrillo Martín de Cáceres 1989-1990, 115.

16. MAdOz 1846, 306. 
un estudio sistemático de sus fuentes epigráficas para la publicación de la magna obra de Hübner, el Corpus Inscriptionum Latinarum ${ }^{17}$.

El estudio del pasado de Cáparra experimentó un gran desarrollo durante el siglo xx. J. R. Mélida indicó la existencia de esta antigua ciudad romana en el capítulo dedicado a la provincia de Cáceres en su Catálogo Monumental de España ${ }^{18}$. Poco después tuvieron lugar las primeras intervenciones arqueológicas dirigidas por A. Floriano entre 1929-193019. Estas excavaciones ayudaron a conocer el perímetro urbano de Capera, así como la ubicación de algunos de sus edificios más importantes y de las necrópolis. Unas décadas después, J. M. Blázquez organizó una serie de campañas en las que se excavó el arco, los accesos al foro y determinados sectores del anfiteatro ${ }^{20}$. En los años setenta, A. García y Bellido realizó un estudio pormenorizado sobre el arco cuadrifronte y elaboró una reconstrucción hipotética de cómo debía de ser este monumento en su origen ${ }^{21}$. Las excavaciones se reiniciaron en 1985 gracias al impulso llevado a cabo por el Área de Arqueología del Departamento de Historia de la Universidad de Extremadura. Asimismo, la Diputación Provincial de Cáceres adquirió una buena parte de los terrenos de la antigua ciudad romana y, a partir de entonces, se realizaron diversas intervenciones con el apoyo de la Consejería de Educación y Cultura de la Junta de Extremadura. E. Cerrillo dirigió algunas excavaciones en el foro, en el anfiteatro y en algunas zonas domésticas ${ }^{22}$. Junto a J. M. Fernández y A. Alonso, E. Cerrillo también se encargó del estudio del poblamiento rural en su territorio de influencia ${ }^{23}$. A mediados de los noventa, A. NüennerichAsmus publicó su investigación sobre el arco honorífico de Cáparra desde el punto de vista arquitectónico ${ }^{24}$. Posteriormente, el yacimiento se integró en el proyecto de rehabilitación integral del Patrimonio Extremeño

17. El volumen segundo está dedicado a Hispania. La obra cuenta con una sección sobre Cáparra y las inscripciones que procedían de este lugar.

18. Mélida y Alinari 1924, 96.

19. Floriano Cumbreño 1944, 270.

20. Blázquez Martínez 1965; 1966; 1968.

21. García y Bellido 1972, 45-90.

22. Cerrillo Martín de Cáceres 1995, 311-326; 1998, 77-92. E. Cerrillo ha publicado numerosos trabajos de investigación sobre esta ciudad y puede ser considerado el mayor especialista en el conocimiento de la antigua Capera. Algunos de sus estudios los podemos encontrar en la bibliografía final.

23. Alonso Sánchez, Cerrillo Martín de Cáceres y Fernández Corrales 1992-1993, 67-88. Anteriormente, J. M. Fernández ya había llevado a cabo también un estudio de la ciudad y de su territorio a través de los análisis espaciales tan de moda a finales de los ochenta. Véase FerNÁNDEZ CoRRALES 1988.

24. NÜNNERICH-Asmus 1996. 
"Alba Plata» (1998-2004). La construcción de un centro de interpretación y la realización de una serie de campañas arqueológicas, dirigidas por A. Bejarano y E. Gijón, se incluyeron dentro de las actuaciones de este proyecto. Además, numerosos investigadores han mostrado su interés por el corpus epigráfico de la ciudad. R. Thouvenot, J. M. Roldán, R. Hurtado, A. Stylow, S. Haba, V. Rodrígo, M. González, A. Álvarez o J. Esteban, entre otros, bien directa o indirectamente, han analizado las inscripciones procedentes de este lugar en sus trabajos ${ }^{25}$. Faltaba, por tanto, abordar desde un punto de vista general la sociedad y la economía de esta ciudad en época antigua.

\section{LA SOCIEDAD DE LA CIUDAD ROMANA DE CAPERA}

\subsection{La élite local y su proyección en la ciudad}

M. Fidius Macer fue un caperense que pertenecía al sector privilegiado de la sociedad local que vivió la transformación de civitas stipendiaria a municipium y se benefició del cambio. Antes de la concesión, Macer había desempeñado el cargo de magister en tres ocasiones y, posteriormente, fue duumvir dos veces con la nueva categoría municipal ${ }^{26}$. De este modo, él ocupó las magistraturas más importantes del gobierno local. Su cursus honorum fue recogido en un epígrafe que alude a una dedicación a la diosa Augusta Trebaruna ${ }^{27}$. El sillar en el que se sitúa la inscripción podría haber servido de dintel y pertenecería a un edificio que habría sufragado el propio Macer en honor a esta divinidad indígena ${ }^{28}$. No habría sido su único acto de evergestimo. El arco cuadrifronte también fue construido por él ${ }^{29}$. Sus características demuestran el importante poder adquisitivo de la familia de Macer. Además, el arco estaba decorado con una serie de pedestales con inscripciones y estatuas. Uno de los epígrafes hace referencia a dos individuos, Bolosea Pelli f(ilia) y Fidius Macri f(ilius), los padres de M. Fidius Macer ${ }^{30}$. Él cumplió con la voluntad de

25. Thouvenot 1940, 529-531; Roldán Hervás 1965, 5-37; Hurtado de San Antonio 1977; Stylow 1986, 303; Haba Quirós y Rodrigo López 1986, 43-60; González Herrero 2002, 417 434; 2004, 365-384; Álvarez Melero 2008, 69-97; Esteban Ortega 2013; 2017a, 95-112; 2017b: 179-197.

26. $C P I L C 818=$ HEp 12, 2002, $93=A E$ 1967, $197=A E$ 1987, $616=A E 2002,705=$ CILCC III, 1014.

27. Cidoncha Redondo 2016, 161-162

28. Cerrillo Martín de Cáceres 2000, 161-162.

29. Floriano Cumbreño 1944, 274; NünNerich-Asmus 1998, 23.

30. CIL II, $834=$ CPILC $183=$ CILCC III, 1003. 
sus progenitores de edificar este monumento honorífico. La construcción tenía como finalidad ensalzar el honor y el prestigio de su gens, junto con la perpetuación de su memoria en la comunidad local.

El ejercicio de un cargo municipal conllevaba una serie de derechos y de beneficios, entre los que destacaba la concesión de la ciudadanía para el que había desempeñado la magistratura, así como para su familia ${ }^{31} . M$. Fidius Macer obtuvo ese privilegio al ocupar una serie de cargos locales, comenzó a emplear los tria nomina y fue adscrito a la tribu Quirina. Sus ascendientes directos eran de origen peregrino como podemos intuir por su onomástica. Tanto su padre, Fidius Macrif(ilius), como su madre, Bolosea Pelli f(ilia), habrían fallecido antes de poder disfrutar de la concesión de la ciudadanía. Por tanto, la onomástica de M. Fidius Macer hace referencia tanto a su padre como a su abuelo a través de su nomen y de su cognomen, aunque la estructura de su propio nombre es ya plenamente romana. Ellos no son los únicos miembros que conocemos de su familia, ya que su esposa, Iulia Luperca Luperci f(ilia), también fue aludida en otra inscripción ${ }^{32}$. Probablemente, ella perteneció a otra familia destacada de la élite provincial ${ }^{33}$.

Macer debió de realizar todo el cursus honorum a nivel local y consiguió ocupar el cargo de praefectus fabrum, lo cual supondría el comienzo de la carrera ecuestre. M. González alude a la costumbre, sobre todo a partir de época flavia, de que este cargo fuera ocupado por individuos que habían disfrutado de una destacada trayectoria política en el ámbito local $^{34}$. A su vez, la misma autora plantea la posibilidad, no confirmada, de que esta referencia pudiera estar relacionada con un collegium fabrum f $^{35}$. Por su parte, A. Álvarez defiende que no hay que confundir el cargo que ocupó Macer con el de praefectus collegii fabrum ${ }^{36}$. Seguramente, el puesto de praefectus fabrum sería el último desempeñado por Macer y su carrera política pudo haber quedado interrumpida por diferentes motivos. Uno de ellos podría haber sido su avanzada edad o, tal vez, su propia muerte. P. Guichard opina que su promoción al grupo ecuestre pudo estar relacionada con la labor de monumentalización que él llevó a cabo en el municipium ${ }^{37}$.

31. Lex Irn., 21; ROLDÁN HERVÁs 1998, 45.

32. CIL II, $835=$ CILCC III, 1004 .

33. Salinas de Frías y Rodríguez Cortés 2000, 26; Álvarez Melero 2008, 75, 78; Esteban Ortega 2017a, 95-112; Cidoncha Redondo 2018, 108.

34. González Herrero 2004, 366. Sobre la promoción de las élites autóctonas, véase el trabajo realizado por RodríGuez NeILA 1981, 89-118.

35. González Herrero 2004, 366.

36. Álvarez Melero 2008, 76.

37. Guichard 1994, 253. 
Podemos constatar la presencia de otro posible duumvir junto con el anterior, aunque las condiciones de conservación de la pieza impiden contar con el texto completo. Estaríamos ante un individuo que podría llamarse P. Mem[mius ---] Ligus[tinus ---] o, quizás, P. Mem[mius ---] Ligus[tini (filius)---] Ta[ncinus?---], según las diferentes interpretaciones de lectura ${ }^{38}$. J. Esteban cree que él procedería del ámbito local a juzgar por su onomástica $^{39}$. De esta manera, su familia habría formado parte de los grupos privilegiados de Capera y sus miembros desempeñarían funciones en el gobierno de la ciudad. La placa de mármol en la que se conserva su nombre se halló durante las excavaciones arqueológicas realizadas en el foro del municipio ${ }^{40}$. El texto debió de mencionar algún acto evergético como, por ejemplo, la colocación de una estatua de P.Memmius, ya que él fue el beneficiario del homenaje. En este lugar público se han localizado huellas de la presencia de pedestales que soportarían las imágenes de emperadores, de miembros de la familia imperial o de individuos destacados de la localidad, entre los que podría estar el protagonista de la inscripción.

Existe también una mención al ordo decurionum en su conjunto. Se encontraba en un epígrafe datado entre los años 197 y 211 en el que se decretaba una serie de honores a Julia Domna, la esposa del emperador Septimio Severo ${ }^{41}$. El texto sufrió una damnatio memoriae, ya que el nombre de Geta fue eliminado. Julia Domna aparece con uno de los títulos honoríficos a los que estaba asociada, mater castrorum, epíteto frecuente tanto en la epigrafía como en la numismática ${ }^{42}$. Precisamente, junto con la mención al ordo decurionum, se incide en la pertenencia de este grupo sociopolítico a la ciudad de Capera y así queda indicado en el texto. Además, se realza la posición superior de este conjunto de ciudadanos al estar vinculado con el epíteto splendidissimus, expresión asociada a este grupo sobre todo en el siglo III $^{43}$. La inscripción honorífica se encontraría situada en un pedestal bajo una estatua con la imagen de la esposa del primer emperador severo. La finalidad de este homenaje sería manifestar el respeto del municipio a un importante miembro de la gens imperial.

Las familias de la élite local poseyeron un cierto nivel económico para ser capaces de colocar a sus miembros en las magistraturas del municipio y, al mismo tiempo, poder sobrellevar los gastos derivados de la carrera política. Como estamos viendo, ellas sufragaron también algunos actos

38. $A E$ 1998, $721=$ HEp 8, 1998, $89=$ HEp 9, 1999, $252=$ CILCC III, 1010.

39. Esteban Ortega 2013, 97-98.

40. Cerrillo Martín de Cáceres 2006b, 23.

41. CIL II, $810=$ CPILC 185.

42. Esteban Ortega 2017b, 190-191.

43. Rodríguez Neila 1997, 201-214. 
evergéticos de la ciudad. Una inscripción menciona la construcción de un Aqua Augusta por un individuo llamado Albinus ${ }^{44}$. El texto nos demuestra la existencia de un edificio vinculado con una conducción hidráulica, probablemente, relacionada con un acueducto que abastecía de agua a Capera. También existe la hipótesis de que la inscripción pudiese formar parte de un nymphaeum ${ }^{45}$. El epígrafe ha sido datado entre finales de época flavia y la época trajanea, por lo que coincide, una vez más, con el momento de mayor monumentalización de la ciudad ${ }^{46}$. Precisamente, en la inscripción se hace alusión a la nueva condición de este núcleo urbano: municipium Flavium Cap[erensis]. Desconocemos el nombre completo de Albinus, ya que no se ha conservado, pero estaríamos ante otro personaje destacado del ámbito local en la época en la que se produjo la transformación jurídica de Capera.

L. Valerius Vegetinus fue otro de los miembros importantes de la ciudad, ya que su nombre fue grabado en un pedestal de mármol que sustentaba una estatua dedicada a Iuppiter Optimus Maximus ${ }^{47}$. Su hallazgo se produjo en la zona del foro, por lo que A. Floriano relacionó el espacio en el que apareció la pieza con un templo dedicado al culto de esta divinidad romana ${ }^{48}$. Por su parte, E. Cerrillo considera que estaría situado en otro edificio importante mandado a construir por el propio Vegetinus, como, por ejemplo, la curia municipal ${ }^{49}$.

Hay otros posibles actos de munificencia de los que no contamos con referencias escritas. Un ejemplo de ello podría haber sido la construcción del anfiteatro, situado al sureste de la ciudad, fuera del recinto amurallado. No hay indicios que permitan establecer su datación, aunque, probablemente, se situaría a finales del siglo i o a principios del siglo II d. C. ${ }^{50}$. La presencia de un edificio de este tipo es una clara muestra de la introducción de la población local en las costumbres y en los modos de vida propios de la sociedad romana.

44. $A E$ 1941, $133=$ CPILC $815=A E$ 1986, $307=$ HEp 1, 1989, $158=$ CILCC III, 1002.

45. Cerrillo Martín de Cáceres 2000, 161.

46. STYLOW 1986, 304.

47. $A E$ 1946, $15=$ CPILC $814=$ CILCC III, 1013. Una inscripción funeraria de la ciudad fue dedicada a un niño fallecido llamado C. Val(erius) Vegeltilnus (HEp 15, 2006, 93 = CILCC III, 1061), quizás vinculado con él por lazos familiares. Véase también CiDonCHA REDONDO 2016, 165-166.

48. Floriano Cumbreño 1944, 275.

49. Cerrillo Martín de Cáceres 2006a, 17.

50. Cerrillo Martín de Cáceres 1995, 311. 


\subsection{El alto número de peregrini}

Muchos de los individuos documentados tenían raíces peregrinas según demuestra la onomástica. Es frecuente atestiguar a sujetos que portaban un nombre único seguido de la filiación en genitivo, siempre por vía masculina. Por un lado, nos podemos encontrar a personas con antropónimos de origen indígena, al igual que ocurre con los nombres de sus padres en la filiación. Los casos de Arbura Tancini f(ilia) o Talabus Tangini (filius) son claras muestras de esto ${ }^{51}$. Por otro lado, Vitulus Malgeini f(ilius) o Severus Tangini (filius) son algunos ejemplos de peregrini con nombres de raíz latina, aunque los de sus progenitores seguían siendo indígenas ${ }^{52}$. A pesar de que se observa una evolución progresiva hacia el empleo de la onomástica romana, la sociedad caperense muestra una marcada influencia de su pasado. Incluso, a veces, contamos con individuos que tienen nombres latinos, pero eligen antropónimos indígenas para sus descendientes. Ese fue el caso de Cilea Flavi $f(\text { ilia })^{53}$. La explicación podría estar en el deseo de algunos autóctonos de no olvidar sus raíces indígenas y recordar a sus antepasados.

Conocemos a un gran número de estos peregrini a través de las fuentes epigráficas. En ocasiones, las inscripciones nos muestran a familias de individuos cuya nomenclatura sigue el modelo típico indígena. Por ejemplo, Ambatus Pelli (filius) fue el dedicante de un epitafio a su madre, Arbura Tancini f(ilia), y a su hija, Camira ${ }^{54}$. Todos ellos presentan nombres con claras raíces autóctonas ${ }^{55}$. Burrilus Celti f(ilius) fue otro peregrinus que dejó expresado en su testamento su deseo de realizar un monumento funerario para sí mismo y para su padre, C[e]ltius Anderci $f(\text { ilius })^{56}$. Podemos mencionar otro ejemplo que muestra al matrimonio

51. CIL II, $853=$ CPILC $392=$ CILCC III, 1094; HEp 11, 2001, $142=$ CILCC III, 1144. Para la onomástica, véase Navarro Caballero y Ramírez Sádaba 2003, 98, 313-316, 312.

52. CIL II, $847=$ ILER $4665=$ CPILC $345=A E$ 2005, $768=$ CILCC III, 1041; HEp 14, 2005, $77=$ AE 1989, $403=$ HEp 1, 1989, $148=$ HEp 2, 1990, $203=$ HEp 14, 2005, 77. Sobre los orígenes de la onomástica, véase Navarro Caballero y Ramírez Sádaba 2003, 344, 313-316, 300-303, 224-225.

53. CPILC $256=$ HEp 5, 1995, 208 = CILCC III, 1143. Véase Navarro Caballero y Ramírez SÁDABA 2003, 142, 177.

54. CIL II, $853=$ CPILC $392=$ CILCC III, 1094.

55. Navarro Caballero y Ramírez Sádaba 2003, 83-84, 259-260, 98, 313-316, 131.

56. HEp 13, 2003/04, 231 = CILCC III, 962. Sobre la onomástica, véase NAVARRO CABALLERO y Ramírez Sádaba 2003, 119-120, 140, 88. Otro ejemplo de padre e hijo lo podemos encontrar en el epitafio de Cloutius Dualif(ilius) colocado por su padre, Dualius (CPILC $811=$ CILCC III, 912). Un testimonio semejante, pero entre madre e hijo, es el de Amoena y Servilus Corcor[i]f(ilius) $($ CPILC $750=$ AE 2000, $697=$ CILCC III, 1118). 
formado por Albinus Lubaecif(ilius) y Adernia Maelonis f(ilia), que vivieron entre finales del siglo I d. C. y comienzos de la siguiente centuria ${ }^{57}$. Como se puede observar, la onomástica peregrina seguía siendo habitual a pesar de que habían pasado varias décadas desde la conquista de este territorio por Roma. Otro rasgo indígena de esta sociedad es la existencia de varias gentilitates, organizaciones suprafamiliares bastante frecuentes en el territorio vetón ${ }^{58}$. Entre los ejemplos documentados, la gentilitas de los Gapetici fue una de ellas y se encargó de honrar a los Dioses Lares con un ara votiva ${ }^{59}$. Los componentes de la misma tendrían un antepasado en común y demostrarían, de esa manera, sus lazos familiares y su cohesión social.

Una mujer peregrina consiguió una de las distinciones más importantes que una fémina podía adquirir en el ámbito local: la civitas per honorem. Avita Moderatif(ilia), aunque no era originaria de Capera, debió de pertenecer a una ilustre familia ya fuera por nacimiento o por matrimonio $^{60}$. Su nieta, Cocceia Severa, se encargó de honrar la memoria de su abuela, mostrando el orgullo que sentía hacia su antepasada ${ }^{61}$. La ciudadanía honorífica habría beneficiado a los descendientes de Avita, que ya adoptaron el modelo onomástico romano.

\subsection{La importante presencia de incolae}

Una característica de la sociedad caperense es el alto número de incolae, individuos que habitaban en una ciudad diferente a su lugar de origen por diversas vicisitudes de la vida. Hay nueve clunienses registrados tanto en Capera como en su territorio de influencia ${ }^{62}$. Las dos ciu-

57. HEp 15, 2006, 96 = CILCC III, 1111. Véase también Cidoncha Redondo 2018, 109; Navarro Caballero y Ramírez Sádaba 2003, 79, 216, 222.

58. Navarro Caballero y Ramírez Sádaba 2003, 404-405. Sobre estas estructuras familiares, véase Redondo Rodríguez 1993, 37-53; Salinas de Frías 1994, 287-309; Esteban Ortega 2000, 259 .

59. CIL II, $804=$ ILS $3639=$ HEp 13, 2003/04, $250=$ CPILC $389=$ CILCC III, 1017.

60. CIL II, $813=$ ILS $6901=$ CPILC $186=$ CILCC III, 1005.

61. Otras mujeres de la misma familia también fueron homenajeadas por Cocceia Severa. Ellas fueron su madre, Trebia Procula (CIL II, $814=$ CPILC $371=$ CILCC III, 1007), y su tía, Trebia Vegeta $($ ILER $4781=$ CPILC $1=$ CILCC III, 1006). Todas tenían ya la onomástica típicamente romana, a diferencia de su antepasada.

62. Se han documentado siete varones y dos mujeres clunienses en la sociedad caperense: Attoanus Flavus Acconis f(ilius) (CPILC $652=$ HEp 15, 2006, $104=$ CILCC III, 1138); Caelia Aunia (CIL II, $820=$ ILER $4793=$ CPILC $375=$ CILCC III, 1031); C. Aelius Segonti f(ilius) Gal(eria) Paternus (CIL II, $818=$ CPILC $366=$ CILCC III, 1029); C. Camilius Paternus Gal(eria) (CIL II, $821=$ CPILC $363=$ HEp 9, 1999, $251=$ CILCC III, 1030); L. Aemilius 
dades romanas estaban bastante alejadas, pero hay suficientes pruebas para demostrar que hubo una estrecha relación entre sus habitantes. J. Gómez-Pantoja ha planteado varias hipótesis para explicar la presencia de clunienses en la zona comprendida entre los valles del Duero y del Tajo. Una de ellas tiene que ver con los recursos mineros, que podrían haber llamado la atención de estos individuos ${ }^{63}$. Otro argumento planteado sería la función de mercatus que tendría Capera o la posible existencia del fenómeno de la trashumancia, aspectos que podrían haber motivado la llegada de clunienses ${ }^{64}$.

Hay inscripciones que nos presentan testimonios de incolae procedentes de otros lugares de la Península Ibérica. Dos individuos son originarios de la capital de Lusitania, Augusta Emerita ${ }^{65}$. Asimismo, había inmigrantes de otras poblaciones hispanas como, por ejemplo, Hispalis, Norba o Segobriga, entre otras ${ }^{66}$. No hay ejemplos atestiguados de Caperensis viviendo fuera de esta ciudad, aunque sí se ha documentado el uso del gentilicio en el ámbito local. Un soldado, M. Sulpicius Andaeti f(ilius) Camalus, menciona a Capera como su lugar de origen ${ }^{67}$. Él perteneció a las fuerzas auxiliares del ejército romano, concretamente a un escuadrón de caballería o turma del ala II de los tracios. Camalus perteneció a una unidad militar cuyo nombre no tenía nada que ver con su etnia y podría datarse en torno a la época julio-claudia o trajanea ${ }^{68}$. Tanto

Cariqum (CIL II, 819 = CPILC 376 = CILCC III, 1050); Proculus (HEp 2, 1990, $226=$ CILCC III, 1141); Sedatus Agenais Allonis f(ilius) (CIL II, 822 = CPILC 651 = CILCC III, 1132); Sempronia Firmi f(ilia) Paterna (CPILC 663 = CILCC III, 1140); Titus Baebius [---] (HEp 3, 1993, $116=A E$ 1989, 361a = CILCC III, 925).

63. Gómez-Pantoja 1999, 99-100.

64. Gómez-Pantoja 1999, 103-107.

65. Los Emeritenses son Valeria M(arci) f(ilia) Salvia (CIL II, $824=$ CPILC $364=$ CILCC III, 1026) y L. Publicius L(uci) f(ilius) Pap(iria) Thiamus (CIL II, $823=$ CPILC $348=$ CILCC III, 1025).

66. Hemos clasificado a C. Marcius Clarus Hispalensis (CIL II, $825=$ CPILC $387=$ CILCC III, 1032); Caecilius Vetto Cantisico(m) Segobricen[sis] (HEp 13, 2003-04, $249=$ CILCC III, 1024); Cocceia Celsi f(ilia) Severa Norbensis (CIL II, 813 = ILS 6901 = CPILC 186; CIL II, 814 = CPILC 371; ILER 4781 = CPILC 1); Q. Verruc(i)us Q(uinti) l(ibertus) Gemel[us] Norb(ensis) (CIL II, $828=$ CPILC 655 = CILCC III, 1133); Cilea Flavia f(ilia) Cauriensis (CPILC $256=$ HEp 5, 1995, 208 = CILCC III, 1143); Vitia Ammira Lame(n)sis (CIL II, $885=$ CPILC 62 = CILCC III, 934); Fulvius Rufus Sestatiensis (CIL II, $852=$ CPILC $41=$ AE 1991, 987 = CILCC III, 925); Aburea Hilari f(ilia) Lanciensis (HEp 1, 1989, $180=$ CILCC III, 1098). Otros casos son [---] Lovesi f(ilius) Interamicus (CIL II, $826=$ CPILC $599=$ HEp 1, 1989, 157); Modestus Merus Limic(u)m (CPILC 664); L. Domitius T(iti)f(ilius) Gal(eria) Vetto Otobesani (CIL II, $829=$ CPILC $350=$ CILCC III, 1036).

67. CIL II, $812=$ CPILC $647=$ HEP 2, 1990, $225=A E$ 1989, $401=$ CILCC III, 1131.

68. Roldán Hervás 1974, 279. 
los lusitanos como los vetones gozaron de la fama de «buenos jinetes» en el mundo romano ${ }^{69}$. Su propio cognomen y el nombre de su padre nos indican que tendría un origen indígena ${ }^{70}$. Sin embargo, Camalus habría obtenido la ciudadanía tras licenciarse de la unidad a la que pertenecía. De este modo, habría adoptado el sistema de los tria nomina como demuestra el texto. Su monumento funerario fue realizado ex testamento. S. Haba y V. Rodrigo han planteado varias hipótesis en relación con la muerte de este soldado. Ellas creen que Camalus podría ser un legionario licenciado que había regresado a su tierra de origen en compañía de algunos de sus compañeros, que la unidad no estaría asentada en un sitio muy alejado o que el soldado podría haber fallecido en el campo de batalla ${ }^{71}$. Personalmente me inclino por la opción de que él había vuelto al lugar que lo vio nacer y allí murió siendo ya un veterano.

\subsection{Los libertos y esclavos}

Las inscripciones procedentes de Capera también muestran la presencia de esclavos y libertos entre la población. No son muchos los testimonios localizados, lo cual no implica que este grupo fuera pequeño. El liberto L. Domitius Fortunatus dedicó un monumento funerario a su patrono L. Domitius T(iti) f(ilius) Gal(eria) Vetto Otobesani ${ }^{72}$. El dedicante manifestó en el texto que el encargo fue pagado con su propio dinero, lo que demostraría que tenía un cierto nivel económico para poder recordar a su manumisor. L. Ael(ius) Fortunatus también fue homenajeado con un altar funerario colocado por su liberto L. Ael(ius) Herculanus ${ }^{73}$. Este último había sido nombrado heredero por su antiguo dominus, lo cual indicaría las buenas relaciones que existieron entre ellos.

A veces, contamos con referencias a familias de esclavos liberados. Así, por ejemplo, L. Caecilius Firmo se encargó de costear la estela funeraria en honor a su hijo fallecido, Fronto Minati l(ibertus) $)^{74}$. Tanto el padre como el hijo habían sido manumitidos, aunque pertenecían a diferentes propietarios. Probablemente, Fronto formaba parte de la familia de su madre, la cual también habría tenido un origen servil, y eso explicaría que

69. Roldán Hervás 1968, 100. Conocemos a otro individuo llamado Flavos que fue eques del ejército, aunque no indica a qué cuerpo perteneció (CPILC $259=$ HEp 5, 1995, $207=$ CILCC III, 1142).

70. Navarro Caballero y Ramírez Sádaba 2003, 88, 130.

71. Haba Quirós y Rodrigo López 1986, 50.

72. CIL II, $829=$ CPILC $350=$ CILCC III, 1036 .

73. CIL II, $831=$ CILCC III, 1092.

74. CIL II, $836=$ CPILC $353=$ CILCC III, 1034. 
padre e hijo tuvieran una onomástica diferente. Otra inscripción funeraria fue dedicada a Samacia, la liberta de M. Acil(ius) Front [o], por su hijo Capito $^{75}$. Al tener solamente el cognomen del dedicante, desconocemos cuál sería su verdadero estatus social, pero puede ser que fuera esclavo o liberto, habiendo nacido cuando su progenitora era aún una esclava.

M. Ael(ius) Amarilli(s) podría haber sido otro liberto a juzgar por su cognomen de origen griego, aunque no se indica su condición jurídica en el texto ${ }^{76}$. Él aparece como el dedicante de un epitafio a su esposa fallecida, Pisira Turai f(ilia). Ella, que había nacido en libertad, era una peregrina según su onomástica ${ }^{77}$. Vemos así uniones de parejas mixtas. Igualmente, contamos con casos de esclavos que habían pertenecido a peregrini. Primus Chilonis l(ibertus) y Peculiaris Cessae lib(ertus) son algunos ejemplos que se pueden clasificar dentro de ese grupo ${ }^{78}$. Por los datos que nos ofrecen las inscripciones, no parece que alguno de estos libertos llegara a destacar de manera especial en el ámbito local, ni económicamente ni tampoco socialmente, como sí ocurrió en otras ciudades hispanas.

Tenemos dos casos de esclavos documentados en Capera. El texto de un altar votivo procedente de Baños de Montemayor menciona a Firmus Ammi s(ervus) como su dedicante ${ }^{79}$. El otro epígrafe es funerario y recuerda a una esclava llamada Paternis $^{80}$. Ella había muerto a los cuarenta años y era la hija de la dedicante del epitafio, Iulia Fortunata. La madre era liberta y habría sido manumitida antes que su hija. Al mismo tiempo, ambas habrían tenido diferentes propietarios, ya que Paternis era la serva de Accia Marciana, mientras que Iulia Fortunata habría sido liberada por otra familia al no tener la misma onomástica de la propietaria de su hija.

75. CIL II, $844=$ CPILC $649=$ CILCC III, 1136.

76. CPILC $747=A E 1965,75=$ CILCC III, 1090. Navarro Caballero y Ramírez Sádaba $2003,83$.

77. Navarro Caballero y Ramírez Sádaba 2003, 264, 326.

78. CIL II, 841 = CILCC III, 1056; CIL II, $816=$ CPILC $346=$ CILCC III, 1027. Peculiar[is] Cessae lifb(ertus)] perteneció al collegium de los cul(tores) Lar(um) Pub(licorum) que fueron los encargados de cubrir los gastos de su entierro y el de otro individuo del que solamente sabemos que era peregrinus (CIL II, $817=$ CPILC $361=$ CILCC III, 1028).

79. $E E$ VIII $77=$ CMCC $155=$ CPILC $66=$ CILCC III, 946. Véase también CIDONCHA REDONDO 2016, 171.

80. CPILC 356. Véase también Cidoncha Redondo 2018, 108. 


\section{LA ECONOMÍA DEL MUNICIPIUM FLAVIUM CAPERENSIS Y DE SU TERRITORIUM}

\subsection{Las características del territorium caperensis}

Capera estuvo condicionada, desde el mismo momento de su fundación, por su ubicación en la conocida en la actualidad como "Vía de la Plata", constituyendo una mansio del iter ab Emerita Asturicam ${ }^{81}$. Otros motivos también influyeron en la elección de este lugar. La ciudad se localiza en un terreno situado entre las tierras fértiles de la depresión del río Alagón, afluente del Tajo, y las primeras estribaciones del Sistema Central, próxima a las sierras de Béjar, Gredos y Gata ${ }^{82}$. Igualmente, el territorio de influencia de Capera está atravesado por el río Ambroz, también llamado "río Cáparra», que es un afluente del Alagón. Asimismo, cuenta con otros cursos de aguas en sus cercanías como, por ejemplo, el río Jerte. Por lo tanto, podemos comprobar cómo la necesidad de recursos hídricos estaba cubierta. No obstante, hay investigadores que creen que la presencia de estos ríos no sería un factor decisivo, ya que el caudal de estos es bastante bajo en determinadas épocas del año y defienden la existencia de una conducción de agua para el abastecimiento de la ciudad desde las zonas montañosas más cercanas ${ }^{83}$. Esta hipótesis podría estar relacionada con la presencia de la inscripción que menciona la construcción del Aqua Augusta que ya hemos analizado ${ }^{84}$. El agua procedente de los manantiales también habría sido fundamental para la vida en este lugar.

Tras el fin de las guerras contra los cántabros y astures, junto con el ordenamiento de las nuevas tierras sometidas, se llevó a cabo un proceso de organización territorial al norte de la provincia de Lusitania $^{85}$. El objetivo era la explotación de los recursos y el cobro de impuestos, por lo que era necesaria la existencia de una red de ciudades. Roma se encargaba de recoger los tributos y de marcar los límites territoriales de las civitates peregrinae, mientras que la distribución interna de cada una de ellas era competencia de la comunidad local ${ }^{86}$. No contamos con mucha información escrita sobre cómo era el territorium de Capera. El ager per

81. El Anónimo de Rávena, también llamado Ravennatis Anonymi Cosmographia o Ravennate, menciona a Cappara en el Iter ab Emerita Asturicam (319, 11). Igualmente, la ciudad aparece como Capara en el Itinerario Antonino $(433,7)$ localizada entre Rusticiana y Caeolinico.

82. Fernández Corrales 1988, 136.

83. Alonso Sánchez, Cerrillo Martín de Cáceres y Fernández Corrales 1992-1993, 72.

84. Véase nota n. ${ }^{\circ} 44$.

85. Ruiz del Árbol Moro 2001, 61.

86. Ruiz del Árbol Moro 2001, 64. 
extremitatem mensura comprehensus, sistema de delimitación empleado sobre el suelo tributario, fue aplicado en otras civitates stipendiariae cercanas como Salmatica o Palantia, según la obra de Frontino ${ }^{87}$. Los límites de estos territorios estarían marcados por termini que, en ocasiones, contaban con inscripciones. Las divisiones internas ayudarían a delimitar las propiedades que se repartían por todo su territorio de influencia. Dos testimonios de este sistema serían los epígrafes localizados cerca de las actuales poblaciones de Aceituna y Montehermoso ${ }^{88}$. Estas petrae notatae indican la existencia de comunidades que no han podido ser identificadas, ya que únicamente se mencionan las iniciales de sus nombres. Ambas aluden al emperador Vespasiano, por lo que datarían de época flavia. E. Ariño defiende que los límites entre estas comunidades fueron establecidos en la etapa augustea sin inscripción alguna, pero, posteriormente, fue necesario remarcarlos como consecuencia de un problema o reclamación que daría lugar a un iudicium ${ }^{89}$.

Algunos investigadores han llevado a cabo determinados estudios relacionados con la Arqueología Espacial en este territorio. Sin embargo, es bastante difícil determinar con exactitud cuáles eran las fronteras precisas de la zona que controlaba una ciudad antigua, por lo que estos métodos han contado tanto con seguidores como con detractores. J. M. Fernández ha sido uno de los investigadores que han utilizado métodos estadísticos, como el índice de Clark y Evans o la conocida fórmula del "vecino más próximo", así como la teoría de Christaller y la aplicación de los polígonos de Thiessen. Según él, el Sistema Central delimitaría el territorio de influencia de Capera en su lado septentrional ${ }^{90}$. La frontera meridional por el oeste estaría marcada por una línea situada entre Capera y Caurium, que partiría desde la sierra de Gata hasta el punto en el que se unen los ríos Tiétar y Tajo ${ }^{91}$. Por su parte, el lado suroriental quedaría limitado por la cuenca del Tiétar, que separaría los territorios de influencia de Capera y Augustobriga92.

87. Frontin. Th., 1-2. Véase también ARIÑo GIL 2005, 95.

88. HEp 12, 2002, 92 = AE 2002, 76; HEp 1, 1989, $149=$ HEp 12, 2002, $88=$ AE 2002, 707.

89. AriÑo Gil 2005, 108; AriÑo Gil y Paule Rubio 2001-2002, 417.

90. Fernández Corrales 1988, 126.

91. Fernández Corrales 1988, 126.

92. Fernández Corrales 1988, 127. 


\subsection{Capera y las vías de comunicación}

Las vías de comunicación desempeñaron un papel fundamental, ya que vertebraron tanto el territorio como la propia organización de Capera. Este sistema de calzadas garantizaba el control administrativo, económico y militar de las zonas bajo el poder de Roma. Al mismo tiempo, favorecía el abastecimiento de las diferentes áreas urbanas y rurales. Además, una vía supone tanto un medio para facilitar la circulación de personas como para la expansión de ideas que favorecen los intercambios culturales. La ciudad analizada estaba en un lugar de paso necesario para las comunicaciones entre el sur y el norte peninsular, e incluso entre el este y el oeste.

Capera fue una importante parada para el descanso de los viajeros que circulaban por el iter ab Emerita Asturicam. La propia vía constituyó un eje que se tuvo en cuenta en la fundación de la ciudad, convirtiéndose en su decumanus maximus. Podemos comprobar, por lo tanto, la importancia que tuvo esta red de comunicación, ya en una etapa anterior a la creación del núcleo urbano que estamos analizando. La conocida «Vía de la Plata" debió desempeñar un papel destacado en la reorganización jurídica y administrativa de la zona durante los primeros momentos de la dominación romana ${ }^{93}$. Igualmente, esta calzada unía a diversas poblaciones con Augusta Emerita, la capital de la provincia, facilitando la comunicación y el trabajo de los funcionarios enviados para la administración de esta región ${ }^{94}$.

El interés por el mantenimiento de esta calzada se manifiesta en las continuas reparaciones que experimentó en época romana. Los miliarios constituyen una valiosa fuente de información para su estudio, ya que nos ofrecen datos sobre determinadas intervenciones puntuales que se realizaron en ella. C. Puerta ha realizado una interesante investigación sobre los miliarios de la "Vía de la Plata", recogiéndose un total de 189 ejemplares, la mayoría situados entre Augusta Emerita y Salmantica ${ }^{95}$. Muchos provienen del territorium de Capera. La milla $C X$ corresponde con la ubicación exacta de la ciudad y se conservan varios miliarios de diferentes épocas que fueron colocados por Nerón, por Adriano y por uno de los hijos de Constantino $^{96}$. El resto de los miliarios se distribuyen de manera no uniforme entre diversos emperadores y sus hijos ${ }^{97}$. La mayoría pertenecen a

93. Roldán Hervás 2005, 21; Gil Mantas 2015, 109.

94. Saquete Chamizo 2006, 93-94; Gil Mantas 2015, 113.

95. Puerta Torres 2002, 39.

96. $A E$ 1967, 198 = CPILC 699; HEp 14, 2005, 93; HEp 14, 2005, 95.

97. Contamos con ejemplos que mencionan a Tiberio (HEp 14, 2005, $78=$ HEp 10, 2000, 108; HEp 15, 2006, 102), Nerón ( AE 1967, 198 = CPILC 699; CIL II, 4665 = CPILC 707; 
Adriano que, junto a Nerón y a Trajano, fue el que llevó a cabo más intervenciones en este tramo de la calzada ${ }^{98}$. A partir del siglo iv comienzan a disminuir las referencias escritas sobre las labores de mantenimiento realizadas en la vía.

Hay que mencionar la existencia de caminos secundarios que unían el núcleo principal de población con otras zonas de su territorio. S. Haba y V. Rodrigo han estudiado algunas de estas vías que existirían antes de la presencia romana en este lugar y que estarían estrechamente relacionadas con el medio físico ${ }^{99}$. Al mismo tiempo, los caminos unirían a Capera con otras localidades importantes, como Caurium o Augustobriga. Este tejido de comunicaciones necesitó de una serie de infraestructuras que facilitaron el tránsito entre las diversas zonas del territorio caperense. Podemos mencionar, por ejemplo, al conocido como «Puente de Cáparra», que cruza el río Ambroz y se localiza muy próximo a la ciudad. El puente salvaría el obstáculo del río para permitir el discurrir de una vía que uniría Capera con los terrenos en torno al río Alagón ${ }^{100}$.

Toda esta red de caminos hizo posible el tránsito de mercancías y facilitó su distribución, contribuyendo a la llegada de productos de diferentes puntos del Imperio. Al mismo tiempo, favoreció un fluido comercio entre las ciudades de la provincia. Roma desarrolló una colonización agraria de cierta importancia en Lusitania para el abastecimiento de las tropas situadas en el norte de la Península ${ }^{101}$. De ese modo, Augusta Emerita se convirtió en el más importante centro comercial que canalizaba el paso de las mercancías por la "Vía de la Plata». Capera también se encontraba situada en este paso obligado en las rutas terrestres con el norte de la Península. El tráfico comercial entre las provincias hispanas debió de ser constante. El aceite bético y el garum fueron algunos de los productos que llegaron con relativa frecuencia a Capera gracias a estos intercambios $^{102}$. Determinados artículos que circulaban por estas calzadas también

CIL II, 4657), Trajano (CIL II, 4667 = CPILC 709; CIL II, $4672=$ CPILC 716; CIL II, $4673=$ CPILC 717), Adriano (CIL II, 6202; HEp 14, 2005, 93; CIL II, 4658; CIL II, 4659; CIL II, 4661; CIL II, 4662 = CPILC 702; CIL II, 4663; CIL II, 4668; CIL II, 4669), Alejandro Severo (CIL II, 4660; HEp 11, 2001, 138), Diocleciano (CIL II, 4653), Constancio Cloro (HEp 14, 2005, 88 = FE 394), Maximiano y su hijo Máximo (HEp 13, 2003/2004, 211), Constantino y sus hijos $(C I L$ II, $4666=$ CPILC $355=$ CPILC 708; CIL II, $4670=$ CPILC 714; CPILC 745; AE 1977, $436=$ $H A E 1785=C P I L C 711=A E 1985,542 ; E R C M C C$ 57, 47), Magnencio y su hermano Decencio (HEp 14, 2005, 81; AE 1946, 16 = ILER 163).

98. En este sentido, véase Álvarez Martínez y Nogales Basarrate 2004, 255-276.

99. Haba Quirós y Rodrigo López, 1990, 244.

100. Álvarez Martínez 2005, 135; Cerrillo Martín de Cáceres 2008, 364.

101. Morillo Cerdán 2006, 49.

102. Pastor Muñoz 2004, 207. 
tendrían como finalidad satisfacer la demanda de las élites municipales. Un ejemplo de ello podría ser la importación de céramica de paredes finas realizada en la Península Itálica y en el sur de la Galia ${ }^{103}$. Capera ejercería el mismo papel distribuidor con los asentamientos de menor entidad situados en su territorio de influencia.

\subsection{Los recursos del territorium y de zonas próximas}

Los recursos mineros también influyeron en el trazado de las redes de comunicación. La propia Capera habría surgido en un lugar de paso en la ruta que unía la plata explotada en las minas de Riotinto con el Norte de la Península para el abastecimiento de las tropas romanas que luchaban en esa zona ${ }^{104}$. Las minas de plata de Plasenzuela y las auríferas de Las Cavenes o El Maíllo son ejemplos de explotaciones mineras cercanas tanto a la calzada como al núcleo urbano que analizamos ${ }^{105}$. La ciudad ejercería un papel importante en la obtención, en el control y en la protección de los metales procedentes de las zonas vecinas, así como de aquellos que circulaban por la vía romana. Las minas de oro próximas al río Tajo y a sus afluentes, junto con otras regiones de la provincia que eran ricas en minerales, fueron controladas por los emperadores ${ }^{106}$. La supervisión de la explotación de estas comarcas era fundamental para el poder estatal.

Además, las características del suelo del territorio caperense favorecerían el desarrollo de la agricultura en ciertas zonas, aunque no en todas. Los cultivos principales serían los cereales, junto con otros productos obtenidos de la huerta, así como de frutales ${ }^{107}$. No obstante, la ganadería sería la principal actividad económica de esta región. La cría de vacas, ovejas, cabras, cerdos y caballos sería frecuente en este lugar. Las explotaciones agrícolas y ganaderas se extendían, en mayor o menor medida, por todas estas tierras aprovechando los recursos necesarios para su desarrollo. La producción obtenida en los diversos asentamientos rurales sería enviada a Capera para su comercialización. Este poblamiento rural estaba situado, principalmente, en el sector oriental y septentrional, en torno a las tierras más fértiles ${ }^{108}$. La proximidad al iter ab Emerita Asturicam, junto con la

103. Castillo Castillo, De Alvarado Gonzalo, Alonso Sánchez, Molano Brías, Fernández Corrales y Cerrillo Martín de Cáceres 1994, 21.

104. Saquete Chamizo 2010, 395.

105. Ruiz del Árbol Moro y Sánchez-Palencia 2000, 115.

106. Saquete Chamizo 2006, 97.

107. SÁncheZ Moreno 2000, 212

108. Alonso Sánchez, Cerrillo Martín de Cáceres y Fernández Corrales 1992-1993, 84; Rodrigo López 1998, 531. 
presencia de los recursos hídricos, serían factores determinantes para su localización. V. Rodrigo ha señalado la existencia de pocos núcleos cercanos a la ciudad y defiende que los individuos que explotaban estos terrenos habitaban en la propia Capera ${ }^{109}$. Al mismo tiempo, hay que destacar la presencia de otros núcleos de población menores como Baños de Montemayor. Gracias a los epígrafes conservados, sabemos que hubo una estrecha relación entre Capera y esta población, famosa por sus aguas termales ${ }^{110}$.

\section{CONClusiones}

Para la administración del territorio de Lusitania, al igual que para las otras provincias, no bastaba solamente con un centro principal que actuase como capital, sino que eran necesarios otros núcleos urbanos de menor entidad que ayudaran a organizar y controlar a la población local de las zonas más alejadas. La fundación de Capera, situada al norte del conventus Emeritensis, perseguía dicho objetivo aprovechando la existencia de un poblado prerromano en este lugar. Su ubicación en la actualmente conocida como "Vía de la Plata» fue un factor decisivo que influyó en las características de su sociedad y de su economía. La propia calzada fue el eje vertebrador del urbanismo de Capera, convirtiéndose en su decumanus. Esto obligaba a todos los viajeros a atravesarla, fomentando un contacto continuo entre la comunidad local y las personas que circulaban a través de esta vía de comunicación. Como consecuencia, se desarrolló una sociedad bastante abierta que acogía fácilmente a los extranjeros en su seno.

La existencia de una población con fuertes raíces autóctonas se refleja en la sociedad de Capera, sobre todo en la onomástica de los individuos que cohabitaban en ella. La mayoría de los sujetos documentados en las inscripciones son peregrini. Poco a poco, observamos cómo el estrato local adoptó las nuevas formas de comportamiento y su nomenclatura experimentó un cambio en todos los niveles sociales. Su transformación en municipium supuso un momento fundamental tanto para la ciudad como para sus habitantes. Los sectores superiores acogieron con más rapidez las costumbres de la vida romana y se acomodaron fácilmente a la nueva situación. Al mismo tiempo, ellos ocuparon los principales cargos de la administración local y fomentaron un proceso de monumentalización

109. Rodrigo López 1998, 536.

110. Cidoncha Redondo 2016, 168-169. 
acorde con su estatus jurídico. De esta manera, la ciudad se dotó de las infraestructuras propias de una urbe: foro, templos, termas, anfiteatro, etc. A pesar de ello, la sociedad caperense siguió mostrando en las fuentes epigráficas una marcada influencia de su pasado indígena durante estos siglos.

La explotación de los recursos fue otro de los objetivos de su fundación. De esta manera, el núcleo poblacional ejerció un papel destacado en la reorganización territorial y administrativa llevada a cabo en época augustea. El Estado habría fomentado el florecimiento de ciudades como esta para salvaguardar sus intereses en Hispania y obtener los máximos beneficios posibles. Así, desde el punto de vista económico, Capera se encargaría de integrar, controlar y explotar esta región de la provincia de Lusitania. Su función de mansio en una importante vía de comunicación entre el norte y el sur de Hispania contribuyó, en gran medida, a su desarrollo económico durante las tres primeras centurias de nuestra era. Además, el aprovisionamiento de este núcleo urbano favoreció el aumento de las explotaciones agrícolas que tenían como finalidad satisfacer la demanda de una población en crecimiento. Al mismo tiempo, un buen número de individuos procedentes de otros lugares de la Península Ibérica se asentaron en Capera. Probablemente, ellos llegaron aquí buscando los beneficios económicos que ofrecía la explotación de estas tierras y su actividad comercial asociada a una importante calzada romana. Todo esto fue fundamental para su prosperidad, convirtiéndose en una de las principales ciudades de la provincia hasta que comenzó a perder su influencia a finales del siglo III o principios del IV d. C.

\section{Bibliografía}

Almagro Gorbea, M. (1994): «Urbanismo de la Hispania Céltica. Castros y Oppida del centro y Occidente de la Península Ibérica», en Almagro, M. y Bravo, A. M. (eds.), Castros y oppida en Extremadura. Complutum, 4, Madrid, 13-75.

Alonso Sánchez, A.; Cerrillo Martín de Cáceres, E. y Fernández Corrales, J. M. (1992-1993): "Tres ejemplos de poblamiento rural romano en torno a ciudades de la Vía de la Plata: Augusta Emerita, Norba Caesarina y Capara", SHHA, 10-11, 67-87.

Álvarez Martínez, J. M. (2005): «Puentes de la Vía de la Plata y de sus inmediaciones", Anas, 18, 123-151.

Állvarez Martínez, J. M. y Nogales Basarrate, T. (2004): "Calzadas de Lusitania: programación e ideología imperial», en Gorges, J. G.; Cerrillo 
Martín de Cáceres, E. y Nogales Basarrate, T. (eds.): V Mesa Redonda Internacional sobre Lusitania Romana: Las Comunicaciones, Madrid, 255-276.

Álvarez Melero, A. (2008): "Matronae equestres ex prouincia Lusitania ortae", $R B P h, 86,1,69-97$.

Andreu Pintado, J. (2006): «Munificencia y promoción política de las élites hispanas en época flavia: ideología y procedimientos", en Rodríguez NeIla, J. F. y Melchor Gil, E. (eds.): Poder central y autonomía municipal: la proyección pública de las élites romanas de Occidente, Córdoba, 385-415.

AriÑo GiL, E. (2005): «La Hispania Citerior occidental y la Lusitania septentrional entre Augusto y los Flavios: el ager per extremitatem mensura comprehensus", en Sillières, P. (ed.): L'Aquitaine et l'Hispanie septentrionale à l'époque julio-claudienne: organisation et exploitation des espaces provinciaux, Bordeaux, 95-112.

Ariño Gil, E. y Paule Rubio, A. (2001-2002): «Una delimitación territorial de época de Vespasiano: dos inscripciones rupestres en el norte de la provincia de Cáceres (España)", Aquitania, XVIII, 411-419.

Blázquez Martínez, J. M. (1965): Cáparra. Excavaciones Arqueológicas en España, 34, Madrid.

Blázquez Martínez, J. M. (1966): Cáparra II. Excavaciones Arqueológicas en España, 54, Madrid.

Blázquez Martínez, J. M. (1968): Cáparra III. Excavaciones Arqueológicas en España, 67, Madrid.

Calderón Fraile, M. N.; Cano Ortiz, A. I.; Cerrillo Cuenca, E.; Heras Mora, F. J.; Mejías del Cosso, M. D.; Sánchez Barba, M. E. y Silva Cordero, A. F. (2000): «Sociedad y territorio: la evolución de los hábitats desde la Segunda Edad del Hierro a la romanización en la provincia de Cáceres", en Gorges, J. G. y Nogales Basarrate, T. (coords.): Sociedad y cultura en la Lusitania romana, Mérida, 53-72.

Canto y de Gregorio, A. M. (1996): "Oppida stipendiaria: los municipios flavios en la descripción de Hispania de Plinio", CPAM, 23, 212-243.

Castillo Castillo, J.; De Alvarado Gonzalo, M.; Alonso Sánchez, A.; Molano Brías, J.; Fernández Corrales, J. M. y Cerrillo Martín de Cáceres, E. (1994): "Cáparra: las relaciones comerciales a través de su aprovisionamiento cerámico", en Dupré I RAVENTós, X. (coord.): La ciutat en el món romà, Tarragona, 21-23.

Cerrillo Martín de Cáceres, E. (1989-1990): «Cáparra después de los romanos (Historia de una despoblación)", Norba, 10, 109-129. 
Cerrillo Martín de Cáceres, E. (1994): "Leyenda y arqueología de las ciudades prerromanas: Cáparra", en Leyenda y arqueología de las ciudades prerromanas de la Península Ibérica, 2, Madrid, 149-158.

Cerrillo Martín de Cáceres, E. (1995): "El anfiteatro de Cáparra», en Álvarez Martínez, J. M. y Enríquez Navascués, J. J. (coords.): El anfiteatro en la Hispania Romana, Mérida, 311-326.

Cerrillo Martín de Cáceres, E. (1998): "Forvm Mvnicipii Flavii Caparensis", Empúries, 51, 77-92.

Cerrillo Martín de Cáceres, E. (2000): "Capara, municipio romano», en Gorges, J. G. y Nogales Basarrate, T. (coords.), Sociedad y cultura en la Lusitania romana, Mérida, 155-164.

Cerrillo Martín de CÁceres, E. (2006a): «El tetrapylon de Cáparra. Visión histórica y gráfica", Zephyrus, 59, 305-316.

Cerrillo Martín de CÁceres, E. (2006b): «La monumentalización del foro de Cáparra a través de la epigrafía», en VAQuerizo Gil, D. y Murillo Redondo, J. F. (coords.): El concepto de lo provincial en el mundo antiguo: homenaje a la profesora Pilar León Alonso, 2, Córdoba, 13-29.

Cerrillo Martín de Cáceres, E. (2008): "El territorio de Cáparra», en Mangas Manjarrés, J. y Novillo, M. A. (coords.), El territorio de las ciudades romanas, Madrid, 359-372.

Cidoncha Redondo, F. (2016): "Las creencias religiosas en la ciudad romana de Capera", en Cordeiro Macenlle, R. y Vázquez Martínez, A. (eds.): Estudos de Arqueoloxía, Prebistoria e Historia Antiga: achega dos novos investigadores, Santiago de Compostela, 157-175.

Cidoncha Redondo, F. (2018): "Las mujeres en el Municipium Flavium Caperensis", Anas, 25-26 (2012/13), 99-116.

De Masdeu, J. F. (1800): Historia crítica de España y de la cultura española en todo género, 19, Madrid.

Docampo, F. (1544): Los quatro libros primeros de la Crónica general de España, Madrid.

Esteban Ortega, J. (2000): "El proceso de romanización en Lusitania a través de la epigrafía», en Gorges, J. G. y Nogales Basarrate, T. (coords.): Sociedad y cultura en Lusitania romana, Mérida, 249-268.

Esteban Ortega, J. (2013): Corpus de inscripciones latinas de Cáceres III. Capera $[=$ CILCC III], Cáceres.

Esteban Ortega, J. (2017a): "La inscripción de Luperca del tetrapylon de Capera (Cáparra, Cáceres). Hallazgo y cuestiones historiográficas», Veleia, 34, 95-112.

Esteban Ortega, J. (2017b): «Un flaminalis procedente de Riolobos y otras manifestaciones de culto imperial en Capera», CAUM, 25, 179-197. 
FernándeZ Corrales, J. M. (1988): El asentamiento romano en Extremadura y su análisis espacial, Cáceres.

Flórez, E. (1758): España Sagrada, 14, Madrid, 54.

Floriano Cumbreño, A. (1944): «Excavaciones en la antigua Capera, Cáparra, Cáceres", $A E A, 17,270$ y ss.

García y Bellido, A. (1972): «El tetrapylon de Capera (Cáparra, Cáceres)», AEspA, 45-47, 45-90.

Gil MANTAS, V. (2015): "Red viaria y red urbana en la Lusitania imperial», en Álvarez Martínez, J. M.; Carvalho, A. y Fabião, C. (eds.), Lusitania Romana. Origen de dos pueblos, Studia Lusitana, 9, Mérida, 109-118.

Gimeno Pascual, H. (1997): Historia de la investigación epigráfica en España en los siglos XVI y XVII a la luz del recuperado manuscrito del Conde de Cimera, Zaragoza.

Gómez-Pantoja, J. (1999): "Historia de dos ciudades: Capera y Clunia», en Gorges, J. G. y Rodríguez Martín, F. G. (coords.), Économie et territoire en Lusitanie romaine, Madrid, 91-108.

González Herrero, M. (2002): «M. Fidius Fidi f. Quir(ina) Macer, benefactor de Capera", Gerión, 20, 1, 417-434.

GonzÁlez Herrero, M. (2004): «Prosopografía de praefecti fabrum originarios de Lusitania", $R P A, 7,1,365-384$.

Guichard, P. (1994): «Domitien et les cités d'Hispania: les promotions a l'ordre équestre des notables issus des municipes Flaviens", Pallas, 40, 251-267.

Haba Quirós, S. y Rodrigo López, V. (1986): «Aportaciones a la epigrafía latina del área caparense», Norba, 7, 43-60.

Haba Quirós, S. y Rodrigo López, V. (1990): "La Vía de la Plata entre las mansiones Rusticiana y Caecilius Vicus: la Calzada en relación con el asentamiento", en Institución Fernando el Católico (ed.): Simposio sobre la red viaria en la Hispania romana, Zaragoza, 241-252.

Hurtado de San Antonio, R. (1977): Corpus Provincial de Inscripciones Latinas de Cáceres [=CPILC], Cáceres.

Mélida y Alinari, J. R. (1924): Catálogo Monumental de España. Provincia de Cáceres, Madrid.

Morillo Cerdán, A. (2006): «Abastecimiento y producción local en los campamentos romanos de la región septentrional de la Península Ibérica», en Morillo Cerdán, A. (ed.), Arqueología militar romana en Hispania, producción y abastecimiento en el ámbito militar, León, 33-74.

Navarro Caballero, M. y Ramírez Sádaba, J. L. (2003): Atlas antroponímico de la Lusitania romana, Mérida-Burdeos. 
NüNNERICH-Asmus, A. (1998): El arco cuadrifronte de Cáparra (Cáceres). Un estudio sobre la arquitectura flavia en la Península Ibérica, Anejos de AEA, Madrid.

Pastor Muñoz, M. (2004): «Vías de comunicación y relaciones comerciales entre Bética y Lusitania", en Gorges, J. G.; Cerrillo Martín de Cáceres, E. y Nogales Basarrate, T. (eds.): V Mesa Redonda Internacional sobre Lusitania Romana: Las Comunicaciones, Madrid, 195-222.

Ponz y Piquer, A. (1784): Viage de España, 8, Madrid.

Puerta Torres, C. (2002): Los miliarios romanos de la Vía de la Plata, Madrid.

Redondo Rodríguez, J. A. (1993): «Organizaciones suprafamiliares vettonas», en El proceso bistórico de la Lusitania Oriental en época prerromana y romana, Cuadernos Emeritenses, 7, Mérida, 37-53.

Rodrigo López, V. (1998): “Cáparra y su organización territorial: relación campo-ciudad", en Mayer i Olivé, M.; Nolla Brufau, J. M. y Pardo Pastor, J. (coords.), De les estructures indigenes a l'organització provincial romana de la Hispània Citerior, Ítaca Annexos, 1, Barcelona, 529-538.

Rodríguez NeIla, J. F. (1981): Sociedad y Administración Local en la Bética Romana, Córdoba.

Rodríguez Neila, J. F. (1997): "Apparitores y personal servil en la administración local de la Bética», SHHA, 15, 197-228.

Roldán Hervás, J. M. (1965): «Las lápidas votivas de Baños de Montemayor», Zephyrus, 16, 5-37.

Roldán Hervás, J. M. (1968): «Fuentes antiguas para el estudio de los Vettones», Zephyrus, 19, 73-106.

Roldán Hervás, J. M. (1974): Hispania y el Ejército romano, Salamanca.

Roldán Hervás, J. M. (1998): "La administración municipal romana en época imperial», en Hernández Guerra, L. y Sagredo San Eustaquio, L. (eds.), El proceso de municipalización en la Hispania romana, Valladolid, 39-55.

Roldán Hervás, J. M. (2005): "El Camino de la Plata: estado de la cuestión», Anas, 18, 11-27.

Ruiz del ÁRbol Moro, M. (2011): Organización y explotación del territorio en el Noreste de Lusitania en época Altoimperial, Madrid.

Ruiz del Árbol Moro, M. y Sánchez-Palencia, F. J. (2000): "Organización y explotación del territorio en el Noreste de Lusitania: Las Cavenes de El Cabaco", en Oliveira Jorge, V. (coord.): Actas del $3^{\circ}$ Congresso de Arqueología Peninsular, Arqueologia da Antiguidade na Península Ibérica, 6, Braga, 115-130.

SALINAS DE FríAs, M. (1994): "Onomástica y sociedad en la epigrafía antigua de las provincias de Salamanca y Ávila», Zephyrus, 47, 287-309. 
Salinas de Frías, M. y Rodríguez Cortés, J. (2000): "Substrato y romanización de las oligarquías locales de la provincia romana de Lusitania", en Gorges, J. G. y Nogales Basarrate, T. (coords.), Sociedad y cultura en la Lusitania romana, Mérida, 17-33.

SÁnchez Moreno, E. (2000): Vetones: bistoria y arqueología de un pueblo prerromano, Madrid.

Saquete Chamizo, J. C. (2006): «El gobernador provincial de Lusitania y sus actividades: viajes, calzadas, conventus y relaciones sociales", en Rodríguez Neila, J. F. y Melchor Gil, E. (eds.): Poder central y autonomía municipal: la proyección pública de las élites romanas de Occidente, Córdoba, 81-112.

Saquete Chamizo, J. C. (2010): "La génesis de Lusitania y los intereses económicos del Emperador", en Gorges, J. G. y Nogales Basarrate, T. (coords.): Naissance de la Lusitanie romaine: (I av.-I ap. J.-C.): VII Table Ronde Internationale sur la Lusitanie romaine, Toulouse-Mérida, 391-403.

STYLow, A. U. (1986): "Apuntes sobre epigrafía de época flavia en Hispania», Gerión, 4, 285-312.

Thouvenot, R. (1940): "Notes sur trois inscriptions Lusitaniennes», REA, 42, 529-531. 
